\title{
BMJ Open Culture and understanding the role of feedback for health professions students: realist synthesis protocol
}

\author{
Paul Douglas Fullerton (D) , ${ }^{1,2}$ Mahbub Sarkar (D) , ${ }^{3}$ Shamsul Haque (D) , ${ }^{4}$ \\ Wendy McKenzie ${ }^{5}$
}

To cite: Fullerton PD,

Sarkar M, Haque S, et al.

Culture and understanding

the role of feedback for health professions students: realist synthesis protocol. BMJ Open 2022;12:e049462. doi:10.1136/ bmjopen-2021-049462

- Prepublication history and additional supplemental material for this paper are available online. To view these files, please visit the journal online (http://dx.doi.org/10.1136/ bmjopen-2021-049462)

Received 25 January 2021 Accepted 26 January 2022

Check for updates

(C) Author(s) (or their employer(s)) 2022. Re-use permitted under CC BY-NC. No commercial re-use. See rights and permissions. Published by BMJ.

For numbered affiliations see end of article.

Correspondence to Dr Paul Douglas Fullerton; paul.fullerton@monash.edu

\section{ABSTRACT}

Introduction Clinical education has moved to a 'competency-based' model with an emphasis on workplace-based learning and assessment which, in turn, depends on feedback to be effective. Further, the understanding of feedback has changed from information about a performance directed to the learner performing the task, to a dialogue, which enables the learner to act and develop.

In health professional education, feedback is a complex interaction between trainee, supervisor and the healthcare system. Most published research on feedback in health professional education originates in Europe and North America. Our interest is on the impact of Culture on this process, particularly in the context of Asian cultures. The (scientific) realist approach of Pawson and Tilley provides a means to examine complex interventions in social situations, and thus is an appropriate lens to use for this study. This is a protocol for a realist synthesis which asks how, why and in what circumstances do Asian Cultures influence health professional trainees to seek, respond to and use feedback given in the clinical environment, if at all.

Methods and analysis An initial search was performed to help define the scope of the review question and develop our initial programme theory. The formal electronic search was carried out in February 2020 and included: CINAHL, ERIC, Medline and Psyclnfo, and repeated in October 2020. Retrieved articles were imported into Covidence for screening and data extraction, after which components of the Context-Mechanisms-Outcomes configurations will be sought to refine the initial programme theory.

Ethics and dissemination As this study is a literature review, ethics approval is not required.

The findings will be documented in line with the RAMESES (Realist And MEta-narrative Evidence Syntheses:

Evolving Standards) publications standards for Realist syntheses, and we plan to disseminate the findings by means of a peer-reviewed journal article and conference presentation(s).

\section{INTRODUCTION}

Clinical education has moved to a 'competency-based' model with an emphasis on workplace-based learning and assessment which, in turn, depends on feedback to be effective. $^{1}{ }^{2}$ Indeed, Ramani et $a l^{2}$ (p744)

\section{Strengths and limitations of this study}

- The synthesis aims to identify the how and why Asian Cultures may influence feedback seeking and provision to health professional trainees, if at all.

- To our knowledge, there are few studies of feedback seeking and provision to health professional trainees in Asia.

- A Realist approach has the potential to help explain the complex nature of Culture's impact on feedback.

- Only studies published in the English language will be included, so transferability of our findings to nonEnglish speaking environments may be lacking.

- In addition to formal literature database searches, we will need to conduct citation mining to locate other relevant resources.

describe feedback as 'a vital cog in the wheel of competency-based medical education'. Given that feedback is established as an important link in competency-based medical education, this led to our interest in the impact of Culture on the feedback process, understanding of the tools used, and its acceptance by both supervisors and trainees.

\section{Complexity of feedback}

Early definitions of feedback emphasised information giving to change behaviour. ${ }^{3-5}$ In a widely quoted paper, Ende ${ }^{3}$ described feedback as information given to trainees about a particular activity which was meant to guide performance of that or a similar activity in the future. The emphasis was that feedback was something supervisors directed at trainees, preferably after observation of the activity in question. University students commonly complain that they do not receive enough feedback, or that it is done poorly, such that academic staff are advised to 'signpost' when feedback was being given. ${ }^{6}$ Ajjawi and Regehr $^{7}$ suggest that perhaps learners and teachers define feedback quite differently.

Over time, feedback has been understood as more than simply providing 
information-information is only feedback when it is used to improve work or learning and is part of a sociocultural interaction. Furthermore, feedback value is influenced by the credibility of the feedback source. ${ }^{8-10}$ As it is essential to close the feedback loop, we can think of feedback as sense-making in the context of information provided from many sources to improve work and learning. ${ }^{11}$ The importance of relationships and trust between the supervisor and trainee, especially when the feedback relates to assessment, has been emphasised. ${ }^{12}$ Many factors influence the effect of feedback including context (eg, the workplace-hospital or ambulatory settings, teaching a skill, formative assessment, summative assessment) ${ }^{13} 14$ regulatory focus, ${ }^{15}$ and self-efficacy ${ }^{16}{ }^{17}$ A person's 'theory of intelligence' (their understanding of whether intelligence is 'fixed' or 'improvable') will also impact-if a person's belief is that intelligence is fixed, effort may not seem to be worthwhile, whereas if they feel there is opportunity for improvement, effort becomes worthwhile. ${ }^{18} 19$

Feedback within the clinical learning environment is particularly complex and influenced by such things as the workload of providing patient care, hierarchies, time constraints and limited opportunities to observe a student's performance, the student's expectations and engagement with feedback provided, ${ }^{816}{ }^{20}$ as well as the supervisor's experience of feedback during their training and therefore understanding of feedback. These complexities will be recognised by clinical teachers in Western environments, but we suspect are magnified within the Asian setting. ${ }^{21}$

\section{Complexity of culture}

When we consider culture in the context of health professional education there are three prominent and interdependent cultures-the 'big-Culture', the Workplace culture and the Education culture.

Culture (sometimes referred to as 'big-Culture') in this context is defined by Hofstede as

The collective programming of the mind that distinguishes one group or category of people from another ... culture is (a) a collective, not individual, attribute; (b) not directly visible but manifested in behaviours; and (c) common to some but not all people. ${ }^{22}$ ( 558$)$

While there are several classifications of characteristics of Culture, Hofstede's typology is widely used and can help in our understanding of the issues. Initially four dimensions were described, ${ }^{22}{ }^{23}$ with two further dimensions added later: ${ }^{2425}$

1. Individualism-Collectivism.

2. Power Distance.

3. Uncertainty Avoidance.

4. Masculinity-Femininity.

5. Long-term versus Short-term Orientation.

6. Indulgence versus Restraint.

Of these dimensions, Individualism-Collectivism and Power Distance appear to be the most significant
big-Culture influences in the clinical learning environment in South-East Asia. ${ }^{21}$

All authors have experience teaching in health professions education in Asia and Australia in a University with campuses in both Malaysia and Australia. This experience raised the question whether cultural differences may influence our students' learning. A preliminary literature review of feedback within health professional education showed a heavy North American and European focus, and few studies from a South-East Asian perspective, except notably from Indonesia. ${ }^{21}{ }^{26}$ This heightened our questioning of whether cultural factors influence acceptance and engagement with 'dialogic feedback' in an Asian context, and how does it compare with the 'Western' situation? (While some Western studies have included international students/trainees, we contend that students who reached the clinical phase of training have had time and opportunity to adapt to their host country.) In focussing on the Asian region, we can recognise several broad Cultural groups-the 'Confucian Heritage Culture', Indonesian-Malaysian/Muslim cultures, and cultures of the Indian subcontinent, overlaid with the cultural impacts of colonialism. Given the limited literature found in our preliminary search focussing on South-East Asia, we decided to look further afield to include the Middle East (the influence of Muslim learning culture) through to the 'Far East' (the 'Confucian Heritage Culture'). If the cultural background of students/trainees and their teachers/supervisors influences their engagement with feedback, how does it do so? Is it the 'ethnic Culture', the national cultures influenced by their colonial history (eg, for Malaysia, Singapore, Indonesia), ${ }^{27}$ or is it the education system culture (eg, school education, university, or even discipline cultures) that have the predominant effect-or is there no dominant effect?

Workplace culture can be viewed as another cultural layer, particularly in clinical teaching and hospital environments $^{28}$ and potentially interacts with the 'bigCulture'. Medicine around the world tends to be hierarchical and paternalistic. However, within the Asian region teaching by humiliation is common, and in Malaysia the term 'scolding' is commonly used to describe teaching in the clinical environment. Another term often heard in the region is kiasu - particularly applied to students of Chinese ethnicity. According to the Oxford Dictionary, ${ }^{29}$ kiasu refers to a person who is 'governed by self-interest, typically manifesting as a selfish, grasping attitude arising from a fear of missing out on something'. Kiasu is a Hokkien word meaning 'fear of loss'. There are two aspects to kiasu, the negative side of being selfish and grasping, as seen in the Oxford dictionary definition, but there is the positive aspect of being successful through hard work-not evident in that dictionary definition ${ }^{30}$ (Kiasu is related to the concept of 'face', which western stereotypes frequently regard as a characteristic of 'Asian Culture').

The education system clearly has its overarching culture which influenced the students' experiences of school-a 
system that emphasises regular high-stakes examinations from an early stage of schooling. There has been much written about the influence of the 'Confucian Heritage Culture' of learning (CHC) on students from South-East Asia as well as from China, Japan and Korea. In his writings, Confucius saw learning as a means of social change and to overcome social differences, but also placed much emphasis on personal effort. ${ }^{31}$ The Chinese philosophy of education also highlighted a mutually respectful relationship between teacher and learner, with the teacher guiding the learner, rather than pulling the learner along. ${ }^{32}$ This parallels the role of guru seen in the Indian culture of education-with the guru (teacher) nurturing the learner. ${ }^{33} 34$

Malaysia and Indonesia are predominantly Islamic countries; Malaysia is a former British colony, while Indonesia was formerly colonised by the Dutch. Clearly both these aspects of their history have shaped the education system of the respective country and are as important factors as the Confucian heritage. There is a great diversity in Islamic education which impacts the South-East Asian region and interacted with the colonial experiences. ${ }^{35}$ The school culture clearly responds to the education system's overarching culture but adds its own layer. An examination-oriented curriculum was seen as a legacy of the colonial era. ${ }^{36}$

Tertiary education culture varies enormously across the region, from hierarchical approaches to being more collegial (especially in the later stages of the degrees). Student experiences in high school impact their transition to university as they come with an expectation that university would simply be an extension of school-first year medical students in Malaysia clearly started university with the idea that knowledge was fixed and largely unchanging, and that their teachers or lecturers functioned as sources of knowledge who were not to be questioned. Knowledge was facts, and facts were immutable. ${ }^{37}$ As school had emphasised rote learning of fixed knowledge, and an important part of those students' adaptation to university was coming to terms with thinking for themselves. As they move into workplace-based learning, the culture of the medical workplace is likely to have an impact.

\section{METHODS AND ANALYSIS \\ Realist synthesis methodology}

The (scientific) Realist approach was chosen as a methodology that is useful for researching complex interventions in the social environment, such as healthcare and education-interventions that frequently work differently in different environments. ${ }^{38}$ The more 'traditional' methods used in reviews in Medicine and other Health Sciences (such as Systematic Reviews) were felt to not capture or explain the complexities of feedback in the social and cultural environment. The realist paradigm asks: 'What is it about this intervention that works, for whom, in what circumstances, in what respects and how? ${ }^{39} 40$ It seeks to find 'mechanisms (M)' that fire in particular 'contexts $(\mathrm{C})^{\prime}$ to produce the 'Outcomes $(\mathrm{O})$ ' in question-so called CMO Configurations. Realist synthesis or realist review (the terms are used interchangeably) is a theory driven, iterative and explanation-building approach, that usually starts with an initial programme theory (IPT) and uses findings from sources to understand how and why the outcomes have occurred, and therefore refine the IPT. ${ }^{38}$ Interpretation involves looking for both confirming and negating data and explanations.

This synthesis asks what leads can Culture provide, in the Asian health professional education environment, to answer?

1. How, why and in what circumstances do health professional trainees (eg, students and junior doctors) seek, respond to and use feedback given in the clinical environment?

2. What do supervisors (eg, consultants, clinical tutors, preceptors) feel about providing feedback? How do they provide feedback, in what circumstances? Do they see their feedback being used?

3. How do trainees and supervisors perceive feedback?

The review will follow the five steps of a realist review as enunciated by Pawson $e t a l,{ }^{39}$ namely

1. Clarify the scope and purpose of the review question.

2. Search for evidence-commencing with an exploratory search, with subsequent focussing and purposive and 'snowball' sampling.

3. Appraise studies and extract data.

4. Synthesise the evidence to obtain conclusions, and ...

5. Disseminate.

In appraising studies, Relevance is assessed by whether it can contribute to theory building or testing, while Rigour assessment is based on whether the methods which generated a particular piece of data is trustworthy. ${ }^{41}$ Pawson argues that the overall methodological quality of a study is not appropriate grounds for excluding a study in realist reviews-'There are often nuggets of wisdom in methodologically weak studies'. ${ }^{42}$

A Preferred Reporting Items for Systematic Review and Meta-Analysis Protocols checklist has been completed and available as an additional file. ${ }^{43}$

\section{Search strategy}

An preliminary search was performed to define the scope of the review question and develop our candidate IPT. This first search utilised Medline and PsycInfo, searching 'Learner' (and variations), Feedback (and debrief) and Culture (including cross-cultural, ethnic differences, anthropology). In terms of a modified PICo model ${ }^{44}$ developed for Qualitative studies (Population, Intervention, Context) format: P: Learners, I: Feedback, Co: Culture.

The formal electronic search was carried out in February 2020 and included: CINAHL, ERIC, Medline and PsycInfo. Search terms were developed in discussion with a librarian and the research team, with the same broad categories as before, although only articles 
Table 1 Example of search strategy used in Ovid Medline

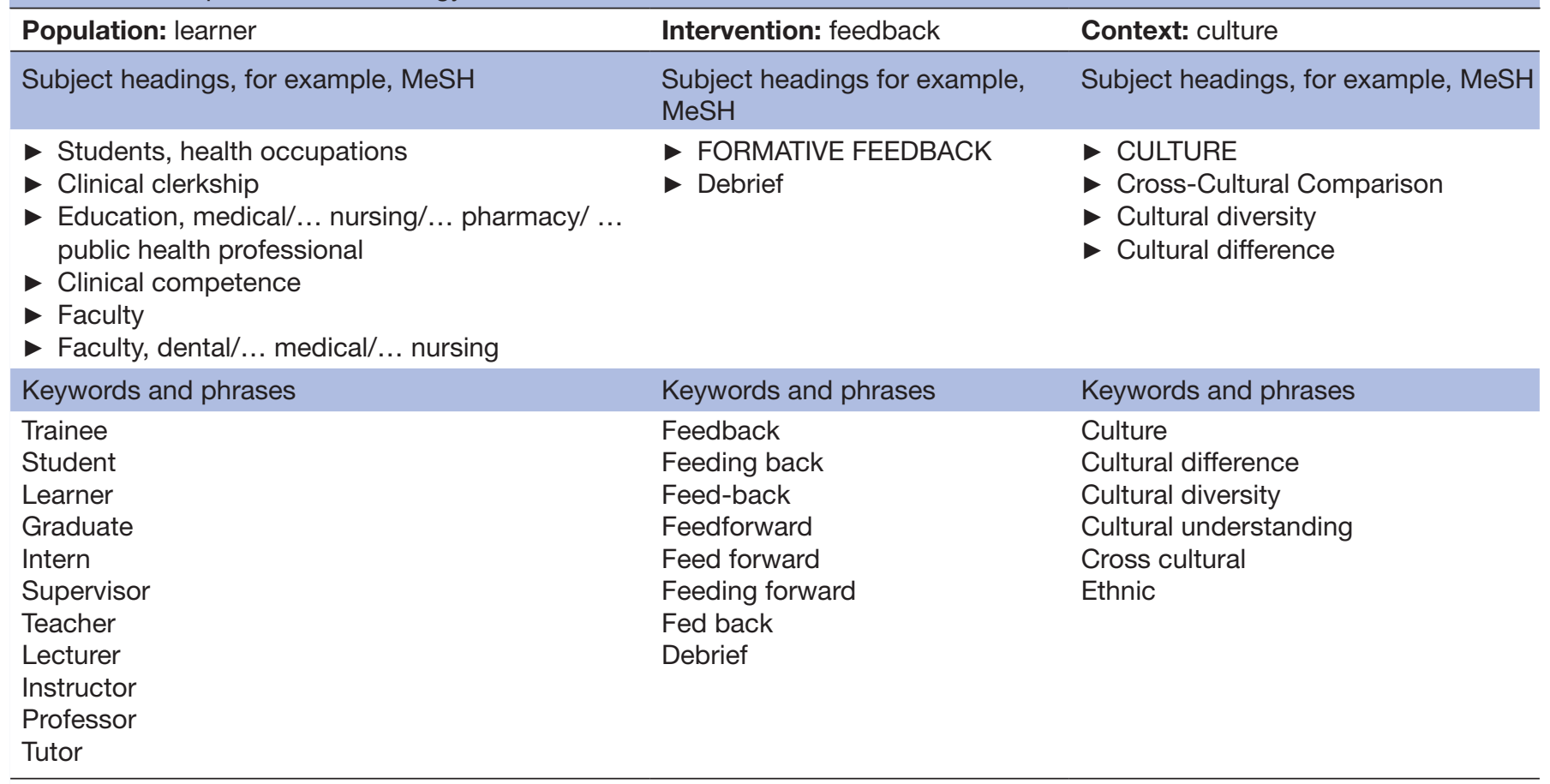

MeSH, Medical Subject Headings - US National Library of Medicine.

available in English were retained. Articles to be considered include qualitative, quantitative and mixed methods, as well as commentaries and review articles. An example of the search strategy is given in table 1 and provided in more detail as a online supplemental file 1 . Both MeSH (Medical Subject Headings) and free text were employed to ensure sufficiently wide article coverage. This search was repeated in October 2020, for articles published since the February search. A hand search will also be made of the following journals: Academic Medicine, Medical Education, Medical Teacher, BMC Medical Education, Education for Health, Teaching and Learning in Medicine, Perspectives on Medical Education, Medical Journal of Malaysia, Annals of the Academy of Medicine Singapore and Singapore Medical Journal. These were chosen as leading health professional education journals and South-East Asian medical journals published in English. Citation mining ('snowball') searches of the reference list in included articles and searching for articles that cite these articles will occur. Although dissertations were initially excluded, relevant published articles arising from the dissertations will be sought by hand-searching for author and a related title.

\section{Selection criteria}

Following the searches as outlined, the citations were imported into Covidence ${ }^{45}$ for title and abstract screening. Duplicates were removed before title and abstract screening began with two team members (PDF and MS) reviewing a sample of the articles retrieved to ensure that criteria are agreed on. Approximately $10 \%$ of retrieved articles were reviewed jointly by the two team members. The rest of this phase was carried out by either of those team members (predominantly PDF) but with the intention to err on retaining studies for closer evaluation at the full text screening stage.

Core inclusion criteria sought studies relating to:

- Workplace-based learning and assessment.

- Feedback giving, seeking and acceptance.

- Culture (ethnic and institutional).

- Post secondary and vocational education involving health professional training.

Exclusion criteria centre around:

- Not related to health professional education.

- Not related to feedback or culture.

- Community health education.

Following title and abstract screening, the full texts of the retained articles were imported into Covidence for further screening. All full-text articles will be screened by two members of the team, and any discrepancies will be discussed to resolve the disagreements. Notes will be made to justify inclusion or exclusion and will assist with both resolving discrepancies and providing transparency. Selecting papers for the review will be guided by the research study questions-Does the study involve students in health professional courses (especially in their clinical training) or their supervisors? Does the study pertain to students in Asian countries?

Studies remaining after the full-text screen will be assessed for Quality and Rigour using the Critical Appraisal Skills Programme (CASP-Qualitative) checklist for Qualitative studies ${ }^{46}$ and the Medical Education Research Study Quality Instrument for quantitative 
studies. ${ }^{47}$ Each study will be appraised by at least two team members-usually PDF and one other. Any discrepancies will be resolved by the full team.

\section{Extracting data}

Data extraction will follow, with data entered into a table within Covidence V.2.0. Data extracted will include citation details, country or region where study was performed, population studied, methodology used, and an empirical judgement of Realist Relevance will also be made at this stage. Comments of potential context, mechanism and outcome will be recorded. Data extracted in Covidence will be exported as a .csv file into Excel, to be used in the synthesis phase. Finally, included articles will be entered into NVivo software ${ }^{48}$ for further data extraction, coding and identification of CMO configurations.

\section{Synthesise findings to draw conclusions}

NVivo software in conjunction with the Excel spreadsheet exported from Covidence will be used to synthesise findings and modify our IPT. The realist approach involves looking for causal mechanisms and how they fire in particular contexts to produce their outcome(s). Data will be extracted from the included papers by the team of reviewers, with a minimum of $10 \%$ of papers being double checked. The data will be tabulated and potential Contexts (C), Mechanisms (M) and Outcomes (O) identified. Discussion among the team members, with the use of realist logic, will aim to further refine those Contexts $(\mathrm{C})$, Mechanisms (M) and find Outcomes patterns (O) to refine our IPT and infer CMO configurations. This process will look for confirming and contradictory findings and will be iterative.

\section{Potential limitations of the realist synthesis approach}

We accept that there are possible limitations of this proposed realist synthesis. First, we have confined our search to trainees in clinical training for health profession disciplines, thus limiting the generalisability outside this sphere of education. Second, our initial interest was in the South-East Asian region but due to paucity of literature from South-East Asia we expanded the geographical scope. However, there is significant overlay of Cultures between the Middle East with the impact of Islam, through to the Far East with the influence of the CHC, as well as the influence of the various colonising powers. Third, we have decided to assess rigour in our screening of articles, but recognise that there is a debate among realist scholars as to the validity of assessing rigour of a whole study-Pawson emphasises that 'nuggets of wisdom' may be found in studies that are methodologically weak. ${ }^{42}$

\section{Ethics and dissemination}

As this study is a literature review, ethics approval is not required.

The findings will be documented in line with the RAMESES (Realist And MEta-narrative Evidence Syntheses: Evolving Standards) publications standards for Realist syntheses, ${ }^{41}$ and we plan to disseminate the findings by means of a peer-reviewed journal article and conference presentation(s).

\section{Implications}

Feedback has been recognised by others, and recognised by us, as critically important in competency-based health professional education, yet feedback is a complex, socially based 'intervention'. Most of the published literature on feedback originates from 'Western' cultures. There is reason to expect that components of culture'big-Culture', workplace culture and education system cultures will impact the provision, acceptability and use of feedback. Again, complex interactions come into play. The realist approach is a relevant way to examine these processes. This protocol and resulting realist synthesis will inform a planned study which aims to provide further information that may lead to improving the usefulness of feedback within the Malaysian context and hopefully will be relevant in the wider Southeast Asian region.

\section{Systematic review registration}

The protocol for this review was judged to be ineligible for registration with the International Prospective Register for Systematic Reviews, as it did not "have a direct and clinically-relevant health-related outcome".

\section{Author affiliations}

${ }^{1}$ Clinical School Johor Bahru, Monash University Malaysia, Johor Bahru, Johor, Malaysia

${ }^{2}$ Faculty of Medicine Nursing and Health Sciences, Monash University, Clayton, Victoria, Australia

${ }^{3}$ Monash Centre for Scholarship in Health Education, Faculty of Medicine Nursing and Health Sciences, Monash University, Clayton, Victoria, Australia

${ }^{4}$ Department of Psychology, Jeffrey Cheah School of Medicine and Health Science, Monash University Malaysia, Bandar Sunway, Selangor, Malaysia

${ }^{5}$ Office of Deputy Dean, Education, Faculty of Medicine Nursing and Health

Sciences, Monash University, Clayton, Victoria, Australia

Contributors PDF developed the original idea for this review protocol in collaboration with MS, WM and SH. PDF wrote the original draft of the protocol, which was subsequently refined by all authors. All authors agree to be accountable for all aspects of this protocol. PDF is guarantor of the protocol.

Funding The authors have not declared a specific grant for this research from any funding agency in the public, commercial or not-for-profit sectors.

Competing interests None declared.

Patient consent for publication Not applicable.

Provenance and peer review Not commissioned; externally peer reviewed.

Supplemental material This content has been supplied by the author(s). It has not been vetted by BMJ Publishing Group Limited (BMJ) and may not have been peer-reviewed. Any opinions or recommendations discussed are solely those of the author(s) and are not endorsed by BMJ. BMJ disclaims all liability and responsibility arising from any reliance placed on the content. Where the content includes any translated material, BMJ does not warrant the accuracy and reliability of the translations (including but not limited to local regulations, clinical guidelines, terminology, drug names and drug dosages), and is not responsible for any error and/or omissions arising from translation and adaptation or otherwise.

Open access This is an open access article distributed in accordance with the Creative Commons Attribution Non Commercial (CC BY-NC 4.0) license, which permits others to distribute, remix, adapt, build upon this work non-commercially, and license their derivative works on different terms, provided the original work is properly cited, appropriate credit is given, any changes made indicated, and the use is non-commercial. See: http://creativecommons.org/licenses/by-nc/4.0/. 


\section{ORCID iDs}

Paul Douglas Fullerton http://orcid.org/0000-0001-7066-4265

Mahbub Sarkar http://orcid.org/0000-0002-6940-3946

Shamsul Haque http://orcid.org/0000-0002-1561-6989

\section{REFERENCES}

1 Norcini J. The power of feedback. Med Educ 2010;44:16-17.

2 Ramani S, Könings KD, Ginsburg S, et al. Feedback redefined: principles and practice. J Gen Intern Med 2019;34:744-9.

3 Ende J. Feedback in clinical medical education. JAMA 1983;250:777.

4 Butler DL, Winne PH. Feedback and self-regulated learning: a theoretical synthesis. Rev Educ Res 1995;65:245-81.

5 Hattie J, Timperley H. The power of feedback. Rev Educ Res 2007;77:81-112.

6 Boud D, Molloy E. What is the problem with feedback? In: Feedback in higher and professional education, 2012: 1-10.

7 Ajjawi R, Regehr G. When I say ... feedback. Med Educ 2019:53:652-4

8 Watling C, Driessen E, van der Vleuten CPM, et al. Beyond individualism: professional culture and its influence on feedback. Med Educ 2013;47:585-94.

9 Watling CJ. Unfulfilled promise, untapped potential: feedback at the crossroads. Med Teach 2014;36:692-7.

10 Wilbur K, BenSmail N, Ahkter S. Student feedback experiences in a cross-border medical education curriculum. Int J Med Educ 2019;10:98-105.

11 Carless D, Boud D. The development of student feedback literacy: enabling uptake of feedback. Assessment \& Evaluation in Higher Education 2018;43:1315-25.

12 Carless D. Trust, distrust and their impact on assessment reform. Assess Eval High Educ 2009;34:79-89.

13 Tekian A, Watling CJ, Roberts TE, et al. Qualitative and quantitative feedback in the context of competency-based education. Med Teach 2017;39:1245-9.

14 Harrison CJ, Könings KD, Schuwirth L, et al. Barriers to the uptake and use of feedback in the context of summative assessment. Adv in Health Sci Educ 2015;20:229-45.

15 Watling C, Driessen E, van der Vleuten CPM, et al. Understanding responses to feedback: the potential and limitations of regulatory focus theory. Med Educ 2012;46:593-603.

16 Ramani S, Könings KD, Mann KV, et al. About Politeness, face, and feedback: exploring resident and faculty perceptions of how institutional feedback culture influences feedback practices. Acad Med 2018;93:1348-58.

17 van de Ridder JMM, Peters CMM, Stokking KM, et al. Framing of feedback impacts student's satisfaction, self-efficacy and performance. Adv in Health Sci Educ 2015;20:803-16.

18 Nussbaum AD, Dweck CS. Defensiveness versus remediation: selftheories and modes of self-esteem maintenance. Pers Soc Psychol Bull 2008;34:599-612.

19 Tweed RG, Lehman DR. Learning considered within a cultural context. Confucian and Socratic approaches. Am Psychol 2002;57:89-99.

20 Harrison CJ, Könings KD, Dannefer EF, et al. Factors influencing students' receptivity to formative feedback emerging from different assessment cultures. Perspect Med Educ 2016;5:276-84.

21 Suhoyo Y, van Hell EA, Prihatiningsih TS, et al. Exploring cultural differences in feedback processes and perceived instructiveness during clerkships: replicating a Dutch study in Indonesia. Med Teach 2014;36:223-9

22 Hofstede G. Cultural differences in teaching and learning. International Journal of Intercultural Relations 1986;10:301-20.

23 Hofstede GJ. Culture's consequences: International differences in work-related values. Beverley Hills, CA: Sage, 1980.

24 Hofstede G, McCrae RR, Personality MRR. Personality and culture revisited: linking traits and dimensions of culture. Cross-Cultural Research 2004;38:52-88.
25 Hofstede G, Hofstede GJ, Minkov M. Part II: Dimensions of national cultures. In: Cultures and organizations: software of the mind. 199. Mc-Graw-Hill Education, 2010.

26 Suhoyo Y, Van Hell EA, Kerdijk W, et al. Influence of feedback characteristics on perceived learning value of feedback in clerkships: does culture matter? BMC Med Educ 2017;17:69.

27 Ratnam-Lim CTL, Tan KHK. Large-Scale implementation of formative assessment practices in an examination-oriented culture. Assessment in Education: Principles, Policy \& Practice 2015;22:61-78

28 Ramani S, Post SE, Könings K, et al. "It's Just Not the Culture": A Qualitative Study Exploring Residents' Perceptions of the Impact of Institutional Culture on Feedback. Teach Learn Med 2017;29:153-61.

29 Oxford English Dictionary. 'culture, n.' OED Online, 2014. Available: http://www.oed.com/view/Entry/45746 [Accessed 06 Aug 2014].

30 Hwang A, Ang S, Francesco AM. The silent Chinese: the influence of face and kiasuism on student feedback-seeking behaviors. Journal of Management Education 2002;26:70-98.

31 Wang T. Understanding Chinese culture and learning. In: Australian Association for Research in Education, 2006: 1-14. http:// publications.aare.edu.au/06pap/wan06122.pdf

32 Jin L, Cortazzi M. Changing practices in Chinese cultures of learning Language, Culture and Curriculum 2006;19:5-20.

33 Marambe KN, Vermunt JD, Boshuizen HPA. A cross-cultural comparison of student learning patterns in higher education. High Educ 2012;64:299-316.

34 Crozet $C$. The core tenets of education in ancient India, inspirations for modern times. International Journal of Pedagogies and Learning 2012;7:262-5.

35 Kadi W. Education in Islam-Myths and truths. Comp Educ Rev 2006:50:311-24.

36 Idrus F. Initiating culturally responsive teaching for identity construction in the Malaysian classrooms. ELT 2014;7:53-64

37 Fullerton PD. 'That's the way we learn': Exploring influences of culture on medical student learning in Malaysia and Australia (MHPE Thesis - Monash University) 2014

38 Wong G, Greenhalgh T, Westhorp G, et al. Realist methods in medical education research: what are they and what can they contribute? Med Educ 2012;46:89-96.

39 Pawson R, Greenhalgh T, Harvey G, et al. Realist review--a new method of systematic review designed for complex policy interventions. J Health Serv Res Policy 2005;10 Suppl 1:21-34.

40 Greenhalgh T, Wong G, Westhorp G, et al. Protocol--realist and meta-narrative evidence synthesis: evolving standards (RAMESES). BMC Med Res Methodol 2011;11:115.

41 Wong G, Greenhalgh T, Westhorp G, et al. RAMESES publication standards: realist syntheses. J Adv Nurs 2013;69:1005-22.

42 Pawson R. Digging for nuggets: How 'bad' research can yield 'good' evidence. Int J Soc Res Methodol 2006;9:127-42.

43 Moher D, Shamseer L, Clarke M, et al. Preferred reporting items for systematic review and meta-analysis protocols (PRISMA-P) 2015 statement. Syst Rev 2015;4:1

44 Lockwood C, Porritt K, Munn Z. Chapter 2: systematic reviews of qualitative evidence. In: JBI manual for evidence synthesis section 2.6.2. JBI, 2020.

45 Veritas Health Innovation. Covidence systematic review software, 2020. Available: www.covidence.org

46 Critical Appraisal Skills Programme. Casp qualitative checklist. 2018. Available: http://www.casp-uk.net/casp-tools-checklists [Accessed 22 Nov 2020].

47 Cook DA, Reed DA. Appraising the quality of medical education research methods: the medical education research study quality instrument and the Newcastle-Ottawa Scale-Education. Acad Med 2015;90:1067-76.

48 International QSR. Unlock insights in your data with powerful analysis NVivo helps you discover more from your qualitative and mixed methods data. uncover richer insights and produce clearly articulated, defensible findings backed by rigorous evidence, 2020. Available: https://www.qsinternational.com/nvivo-qualitative-dataanalysis-software/home 